\title{
A NEW GENUS AND NEW SPECIES OF CHRYSOPIDAE FROM THE WESTERN UNITED STATES, WITH REMARKS ON THE WING VENATION OF THE FAMILY (NEUROPTERA) ${ }^{1}$ \\ By Phillip A. AdAMs \\ Harvard University
}

In some material collected by the writer in southern Arizona in 1949, a single female specimen of a chrysopid was found, representing a previously unknown genus and species. The venation of this genus is remarkably like that of the Chrysopidae described from the Miocene shales of Colorado. Two other recent genera, Triplochrysa Kimmins and Dictyochrysa Petersen, similarly retain an archaic type of venation. Since these latter two genera have not been discussed in the light of the interpretation of the venation given by F. M. Carpenter (1935), they are compared in this paper with the new genus and with the Miocene genera.

\section{Pimachrysa, new genus}

Head: vertex moderately elevated; anterior tentorial pits large; labrum emarginate. Antennae slightly longer than fore wing, scape short, moderately swollen; flagellum filiform, the segments slightly longer than wide. Tarsal claws simple, without basal tooth. Fore wing: costal area rather narrow; subcostal cross-vein basad of origin of $R_{s} ; R_{s}$ arises basad of first intra-median cell. Intra-median cell subtriangular, with apex toward base of wing. Second medio-cubital cross-vein located proximally to furcation of MP. Two graduate series; Psm merges with inner series, strongly zig-zagged; Psc merges

${ }^{1}$ Published with the aid of a grant from the Museum of Comparative Zoology at Harvard College. 
with outer series, not so strongly zig-zagged. Anals not forked, run in a smooth curve to margin of wing. Jugal lobe prominent, one jugal vein present. Hind wing: jugal process small, costal area narrow. MP fused with Rs for a short distance, basal Banksian cell unusually large. Two gradate series; Psm weakly differentiated from inner gradates, not so strongly zig-zagged as in fore wing. Psc merges with outer gradates as in fore wing.

Generotype: Pimachrysa grata n. sp.

This genus is similar in its venation to Triplochrysa Kimmins, from which it may be distinguished by its having the first intra-median cell closed apically by a cross-vein, and by the occurence of only two gradate series in both wings.

Pimachrysa grata n. sp.

Figs. 1-5

Head straw yellow, a shallow groove between bases of antennae black; maxillary and labial palpi pale at base, penultimate segment fuscous, last segment black. Antennae stout; scape pale, with medial, ventral, and lateral surfaces infuscated distally; condyle appears as dark longitudinal line on medial surface; pedicel short, black; flagellum black. Pronotum wide, anterior margin straight; whitish yellow with three fuscous stripes slightly convergent anteriorly. Meso- and metanota yellow, scuta infuscate posterolaterally. Cervical sclerites black; mesoand metapleurae bright yellow, with many areas fuscous. Legs ivory white; femora with a wide fuscous band before the knees. Tibiae slightly infuscated on lateral surface just beyond knee; tarsi a uniform light brown, last segment much darker than preceding. Legs uniformly clothed with short, dark, setae.

Explanation of Plate 2

Pimachrysa grata n. sp. Fig. 1. Wings; im, first intra-median cell; Psm, pseudomedia; Psc, pseudocubitus; b, basal Banksian cell. Fig. 2. Dorsum of head and pronotum. Fig. 3. Terminal abdominal segments of female (lateral view). Fig. 4. Spermatheca (ventral view). Fig. 5. Subgenital plate (ventral view). 

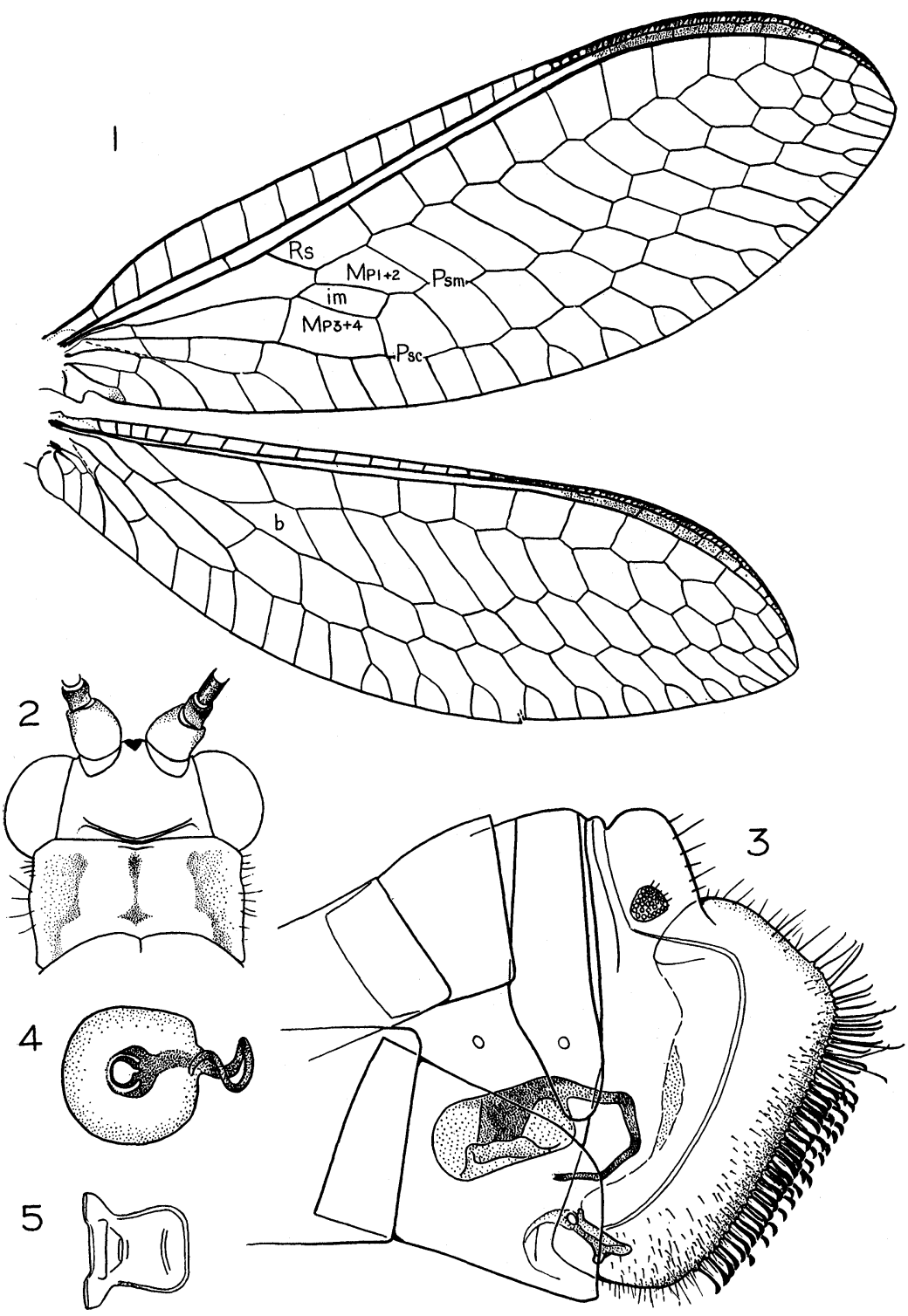

Adams - Pimachrysa grata 
Wings: membrane hyaline, veins slender, setae few, short. Fore wing: costa fuscous near base, otherwise pure white completely around wing. Costal veinlets darkfuscous; Sc white, slightly fuscous basally; $R$ pure white its whole length; stigma white, costal area of stigma densely clothed with short dark setae. All other veins in basal area of wing white as far out as the cubital fork, thence becoming uniformly dark-fuscous. Hind wing: colored about as in fore wing, but with a slightly more extensive area of white veins. Venation as in Figure 1.

Abdomen: short, slender, with terminal segments greatly enlarged. Pale yellow above, with narrow median fuscous stripe, most prominent on second tergite, where it forms an elongate diamond-shaped mark. Sternites brown-fuscous with large central area and posterior margins yellow. Genitalia as in Figures 3-5. Gonapophyses laterales bear on their posteroventral margins three rows of heavy bristles having the ends broadened and strongly reflexed.

Length of antennae, $16 \mathrm{~mm}$.; fore wing, $14 \mathrm{~mm}$.; hind wing, $12.5 \mathrm{~mm}$.; expanse $28.7 \mathrm{~mm}$. ; length of body, $7.5 \mathrm{~mm}$.

Holotype: Madera Canyon, Santa Rita Mts., Arizona, 26 August, 1949, at light. P. A. Adams, collector. In the Museum of Comparative Zoology.

Pimachrysa appears to represent one of a group of relict genera with extremely primitive venation. Carpenter (1935) has revised the fossil Chrysopidae of the Tertiary; the resemblance of these forms to Pimachrysa, and to Triplochrysa and Dictyochrysa, is striking. These three genera are, without doubt, the most primitive of known living chrysopids, at least as regards the wing venation.

A characteristic common to these three genera, differentiating them from both the Tertiary forms and other Recent forms, is the position of the second medio-cubital cross-vein, basad of the furcation of MP. With the exception of Hypochrysa, in all other genera known to the writer, if this furcation is present, the cross-vein connects MP $3+4$ and $\mathrm{CuA}$. Whether this basal position is a primitive or a specialized condition is debatable. 
Paleochrysa, which is otherwise the most primitive described genus, has the quadrangular first intra-median cell characteristic of more advanced genera such as Nothochrysa. On the other hand, the occurence of an intra-median cell formed as in Pimachrysa, Triplochrysa, and Dictyochrysa, in such widely separated areas as North America and Australia, would seem to indicate that the basal position of the second medio-cubital crossvein was broadly distributed in the past. It is entirely possible that the basal position has been secondarily derived; however, the simple bifurcate condition of MP found in these genera certainly appears to represent the more primitive situation. Paleochrysa, Nothochrysa, et $a l$., may then be representative of steps that have occurred in the evolution of more advanced genera, which possess a triangular cell, derived from the quadrangular first intra-median cell by fusion of MP $1+2$ and MP $3+4$. The apex of this type of triangle is directed apicad, not basad as is that of Pimachrysa. In Hypochrysa, since MP $3+4$ fuses with MP $1+2$ as in Chrysopa, the basal position of the cross-vein is presumably secondarily derived.

The first medio-cubital cross-vein of the fore wing is a remnant of a prominent medio-cubital $y$-vein, and is present in all recent Planipennia. Its absence from several of Carpenter's drawings of the Miocene genera seemed significant when viewed in the light of Kimmins' speculation (1952b) that, in the Apochrysinae, the cross-vein found replacing it in its usual position represents instead the remnant of MP $3+4$. An examination of the fossils used in the preparation of these drawings demonstrated, however, that this cross-vein is present in all three of the Miocene genera, and is located in its usual place, opposite the cubital fork.

The subcostal cross-vein has been omitted in Carpenter's drawings, with the exception of Figure 2 (Paleochrysa fracta), in which it should be located slightly distad of the first radial cross-vein, instead of where shown. In Paleochrysa, this cross-vein is always located approximately opposite the first radial cross-vein; in Tribochrysa 
and Lithochrysa, it is much closer to, but still distal to, the origin of Rs. In Dictyochrysa, it is barely proximal to $\mathrm{Rs}$, while in more advanced forms it progresses toward the wing base. The position of this cross-vein in the genera herein treated correlates well with the degree to which archaic venational features are represented. Unfortunately, Martynov's illustration of the Jurassic Mesypochrysa does not include this vein; it would be interesting to see if it then occurred still farther out on the wing than in Paleochrysa.

The distad progression of the origin of $R_{S}$ in the fore wing has been discussed by Carpenter. In all three of the recent relict genera, as would be expected, $R_{S}$ originates basad of the fork of MP.

Members of the Jurassic family Mesochrysopidae demonstrate various degrees of development of the Pseudomedia and the Pseudocubitus. Mesypochrysa has a welldeveloped double gradate series, but both branches of MP run straight toward the wing margin; there is consequently no trace of a Psm or a Psc. Mesochrysa, because of its apically fused Sc and $R$, which results in a rather myrmeleontiod appearance of the wing apex, is to be considered as a specialized side-branch of the chrysopid stem. In this genus, however, both branches of MP show a tendency to turn posteriad, and a weakly developed Psm and Psc are present. The Miocene genera all have developed the strong elbow in the branches of MP characteristic of modern genera; Triplochrysa and Dictyochrysa represent a more primitive condition in this respect, the branches of MP running posteriad in an even curve. Psm and Psc are well developed in the Miocene forms, but retain the archaic zig-zagged condition; Psm in both wings runs into the inner gradate series. In Triplochrysa, the course of Psm has shifted somewhat toward the margin of the wing, and a third, inner, series of gradates occurs. Psc remains in a relatively unspecialized condition, merging with the outer gradates, and showing fairly strong zig-zagging. Psm in more specialized genera has a strong tendency to straighten, so that zig-zagging disappears; 
in genera such as Nothochrysa, this "vein" merges with the outer gradate series, turning up slightly near its end. As the straightening tendency reaches its culmination, e.g. in Chrysopa, Psm runs straight to the margin of the wing, and turns slightly downward near its end. Psc in genera such as Chrysopa may become straightened out basally, and is interrupted by Psm apically.

The writer feels it most unlikely that, as suggested by Kimmins, Dictyochrysa could possibly have been ancestral to Triplochrysa. Admittedly, its venation reflects a most archaic condition. However, in the Planipennia, certain groups frequently become specialized by the multiplication of the number of cross-veins or branches of the longitudinal veins. Examples of this which come readily to mind are the Psychopsidae, Drepanopteryx (Hemerobiidae), and the Palparinae (Myrmeleontidae). These forms frequently retain a most archaic arrangement of veins, and hence furnish quite useful evidence for venational studies. The retention of these primitive characters, however, is not an indication that these forms are unspecialized and therefore eligible to be considered as ancestral to other groups. It is a result of a high degree of specialization by emphasis upon an amplification of the original system of venation, rather than specialization by reduction, or by modification of original pathways of veins by fusion. Dictyochrysa appears to constitute a case of this kind. There is no evidence that the network of hexagonal cells in the apical part of the wings is a primitive character; on the contrary, all the fossil forms have a relatively simple venation, with a normal number of crossveins, and with oblong cells like those of modern representatives of the family. There is therefore no reason to assume that the simple venation of the fossil forms has become complex, as seen in Dictyochrysa, with subsequent reduction to the condition of simplicity seen in Triplochrysa.

It is the writer's opinion that consideration of the venational trends discussed above - the progression basad of the subcostal cross-vein, the apicad migration of $\mathrm{Rs}$, the formation of the first intra-median cell, and the relationship of the gradates with Psm and Psc - can furnish 
much useful information concerning the phylogeny of the Chrysopidae. The archaic expression of these characters in the Recent genera Dictyochrysa, Triplochrysa, and Pimachrysa indicates that they constitute an extremely primitive, although not necessarily closely related, assemblage, similar in many respects to the Miocene genera.

The writer gratefully acknowledges the kindness of Prof. F. M. Carpenter in making possible the examination of fossil Chrysopidae from the collection of the Museum of Comparative Zoology.

\section{Literature Cited}

Carpenter, F. M.

1935. Tertiary Insects of the Family Chrysopidae. Journ. Paleont. $9(3): 259-271$.

Kimmins, D. E.

1952a. Some New Australian Chrysopidae. Ann. Mag. Nat. Hist. (12) $5: 69-81$.

1952b. A Revision of the Genera of the Apochrysinae. Ann. Mag Nat. Hist. (12) 5 :929-944.

Martynov, A. V.

1927. Jurassic Fossil Insects from Turkestan. Bull. Acad. Sci. USSR $21: 757-768$. 

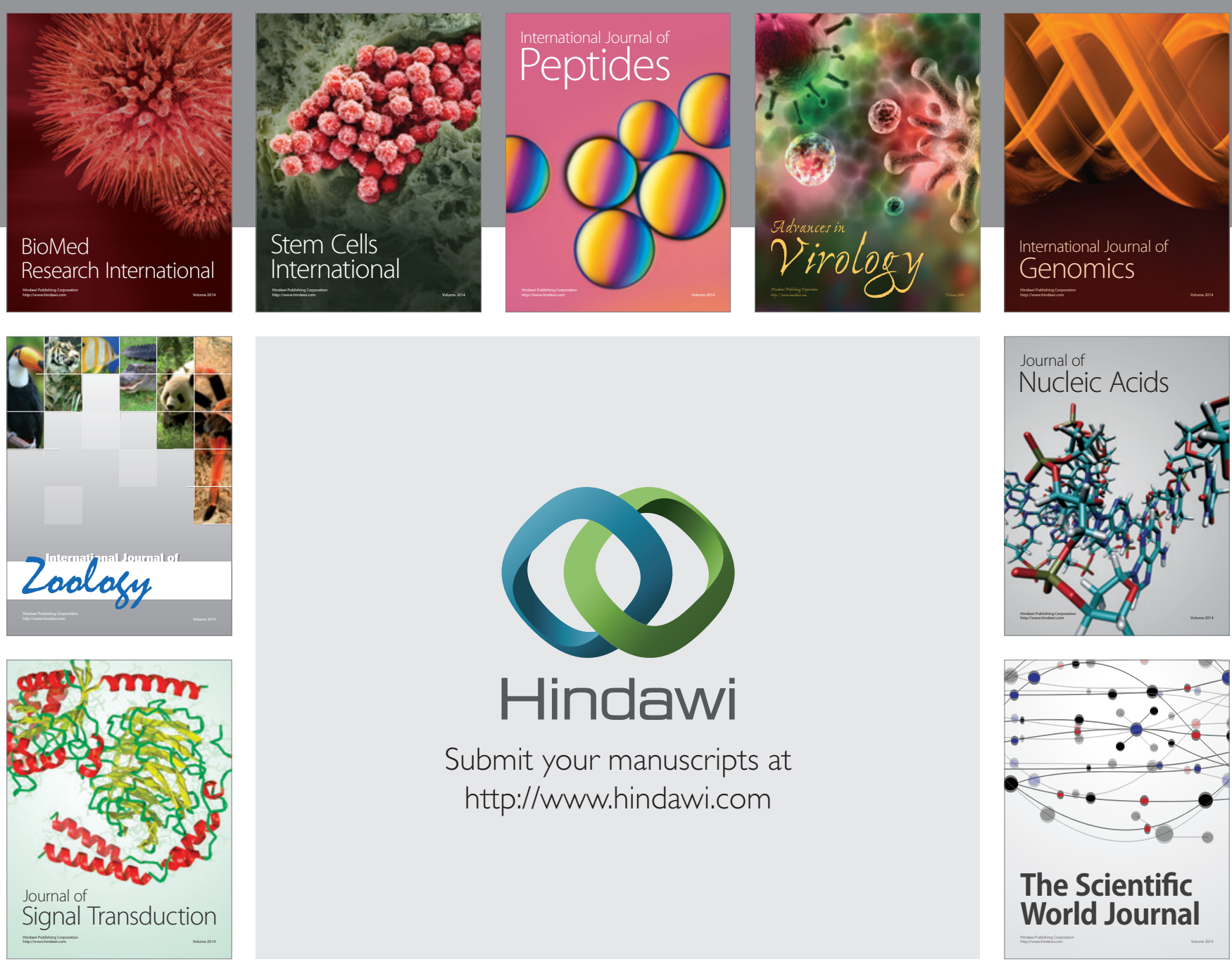

Submit your manuscripts at

http://www.hindawi.com
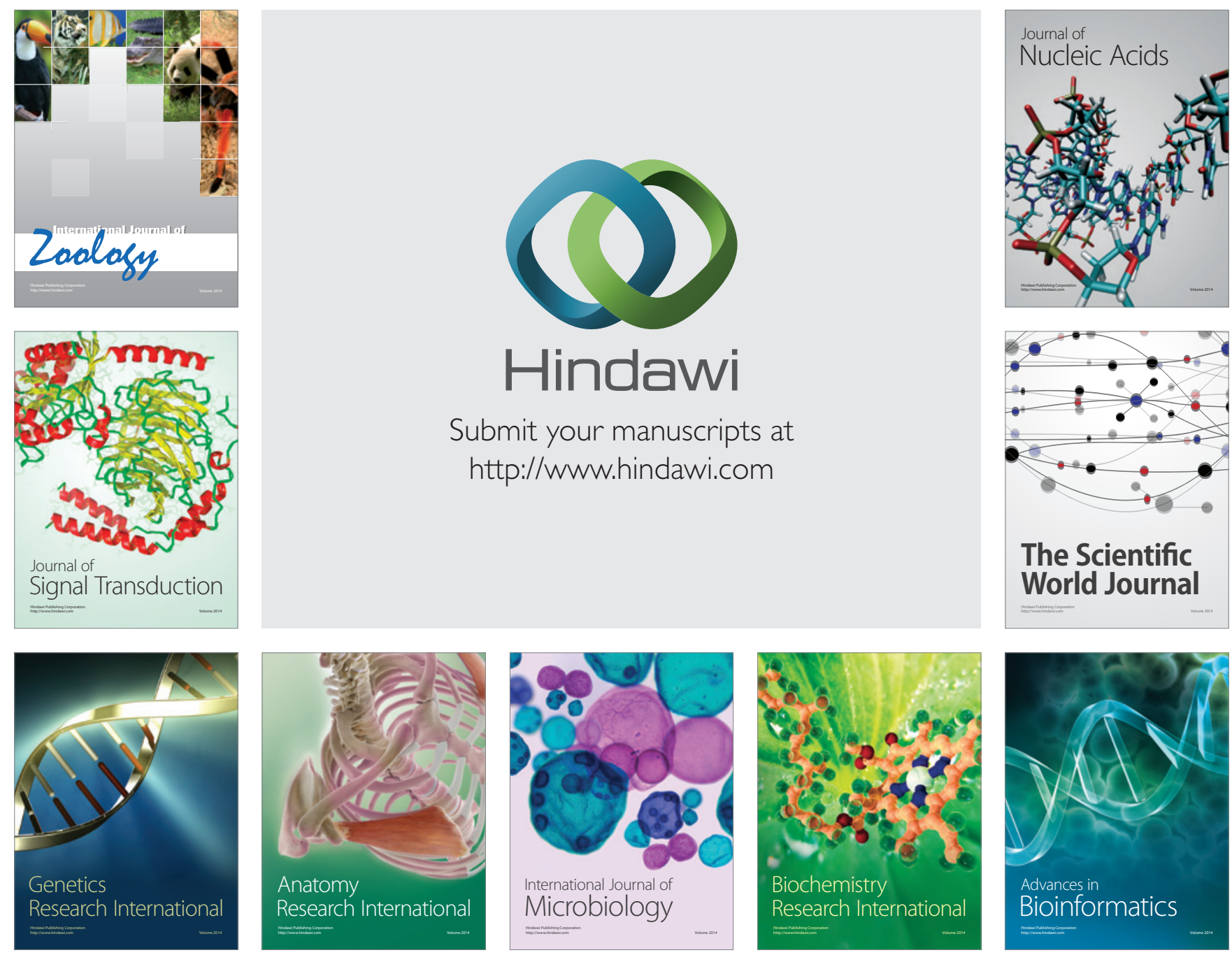

The Scientific World Journal
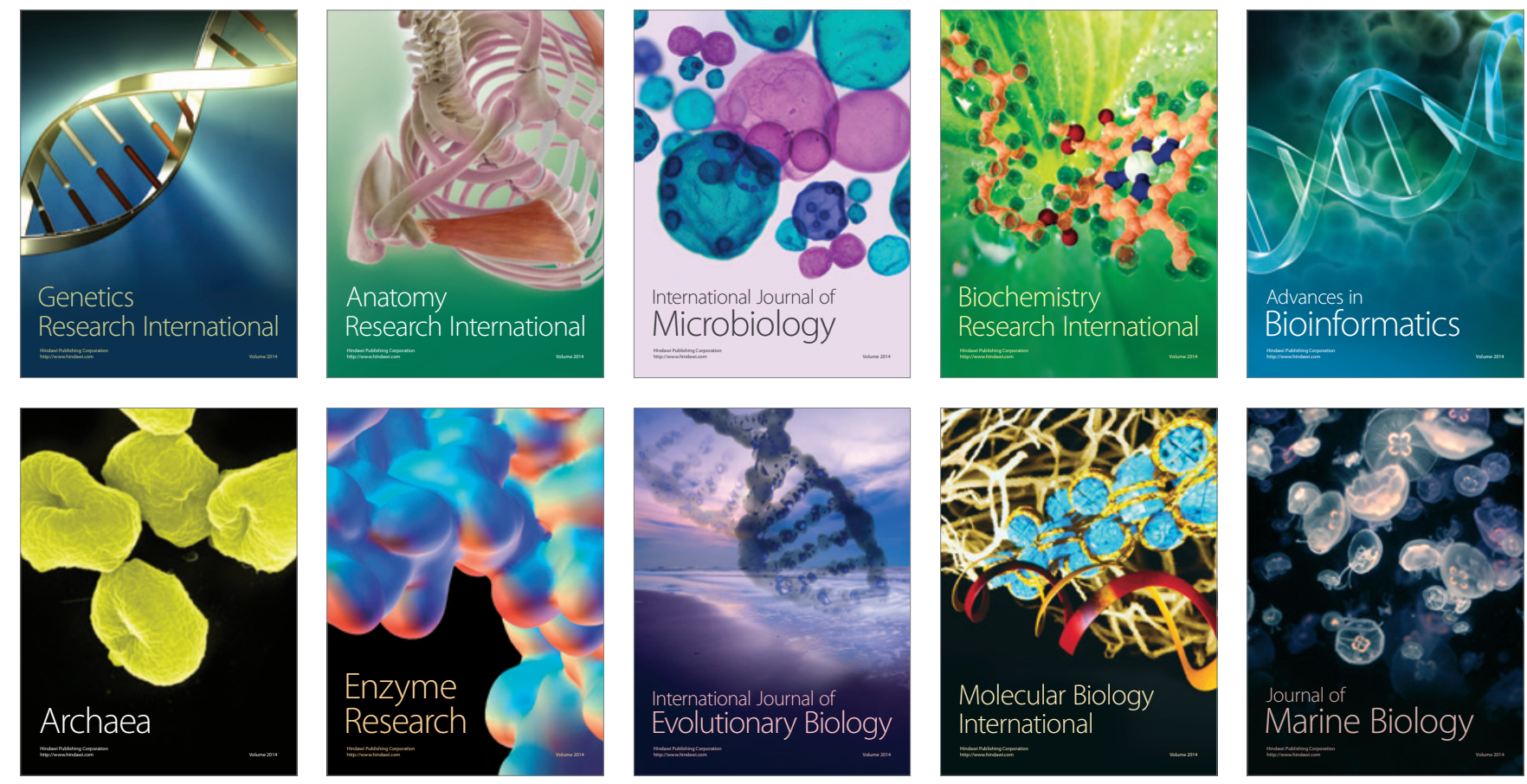